\title{
MODELAGEM DINÂMICA ESPACIAL DA EXPANSÃO DA AGRICULTURA EM CAMPOS NOVOS-SC
}

\author{
Rodrigo de Campos Macedo ${ }^{1}$ \\ Cláudia Maria de Almeida ${ }^{2}$ \\ João Roberto dos Santos ${ }^{3}$
}

\begin{abstract}
Resumo: Modelos computacionais baseados no paradigma de autômatos celulares foram concebidos recentemente para a simulação de mudanças de uso e cobertura da terra, a exemplo de expansão agrícola, processos de desmatamento, crescimento urbano, entre outros. O objetivo do presente trabalho foi o de aplicar e avaliar um modelo de autômatos celulares para simular mudanças de uso e cobertura da terra vinculadas à expansão agrícola no município de Campos Novos/SC. As simulações foram conduzidas para o período de 2003 a 2012, sendo as simulações de 2002 a 2008 retrospectivas, e as simulações de 2009 a 2012 prospectivas. A aplicação do modelo revelou que houve expansão agrícola durante o período analisado, em detrimento de ambientes nativos, tais como matas e campos serranos. Os resultados alcançados revelam o potencial da aplicação dessa classe de modelos para o estudo e a predição de mudanças de cobertura e uso da terra.
\end{abstract}

Palavras-chave: Modelagem dinâmica espacial; Alterações de cobertura e uso da terra; Expansão agrícola.

\section{SPATIAL DYNAMIC MODELING OF AGRICULTURAL EXPANSION IN CAMPOS NOVOS-SC}

\begin{abstract}
Digital models based on the paradigm of cellular automata have been newly conceived for the simulation of land cover and land use change, such as agricultural expansion, deforestation processes, urban sprawl, amongst others. The aim of this study is to run and evaluate a cellular automata-based model designed for simulating land cover and land use change associated with agricultural expansion in the municipality of Campos Novos, Santa Catarina state, south of Brazil. The simulations were run for the time span from 2003 to 2012, where the yearly simulations from 2002 to 2008 are retrospective and those from 2009 to 2012 prospective ones. The conceived model revealed that there was agricultural expansion during the analyzed period, with the simultaneous suppression of native vegetation, such as woods and high fields. The attained results demonstrate the promising potential of this class of models for the analysis and forecast of land cover and land use change.
\end{abstract}

Keywords: Dynamic spatial modeling; Land use and land cover change; Agricultural expansion.

\footnotetext{
${ }^{1}$ Instituto Brasileiro de Geografia e Estatística (IBGE). Email: rodrigo_c_macedo@yahoo.com.br

${ }^{2}$ Instituto Nacional de Pesquisas Espaciais (INPE). Email: almeida@dsr.inpe.br

${ }^{3}$ Instituto Nacional de Pesquisas Espaciais (INPE). Email: jrsantos.inpe@ gmail.com
} 


\section{MODELADO DINÁMICO ESPACIAL DE LA EXPANSIÓN DE AGRICULTURA EN CAMPOS NOVOS-SC}

Resumen: Los modelos computacionales basados en el paradigma de autómatos celulares fueron diseñados recientemente para la simulación de cambios de uso y cobertura de la tierra, a ejemplo de expansión agrícola, procesos de deforestación, crecimiento urbano, entre otros. El objetivo del presente trabajo fue el de aplicar y evaluar un modelo de autómatos celulares para simular cambios de uso y cobertura de la tierra vinculados a la expansión agrícola en el municipio de Campos Novos/SC. Las simulaciones se realizaron para el período de 2003 a 2012, siendo las simulaciones de 2002 a 2008 retrospectivas, y las simulaciones de 2009 a 2012 prospectivas. La aplicación del modelo reveló que hubo expansión agrícola durante el período analizado, en detrimento de ambientes nativos, tales como bosques y campos serranos. Los resultados alcanzados revelan el potencial de la aplicación de esta clase de modelos para el estudio y la predicción de cambios de cobertura y uso de la tierra.

Palabras clave: Modelado dinámico espacial; Cambios de cobertura y uso de la tierra; Expansión agrícola.

\section{INTRODUÇÃO}

A expansão agrícola - especialmente a de monoculturas altamente tecnificadas - pode ocasionar impactos ambientais negativos, tais como perda de biodiversidade e redução de recursos e serviços ambientais, como manutenção de água e de microclima, diminuição de recursos faunísticos e florísticos, perda ou comprometimento de patrimônio paisagístico natural e, principalmente, contaminação de corpos d'água por agrotóxicos (SILVANO et al., 2005; PERRINGS, 2010; CHAKRAVARTY et al., 2012; FREITAS; BELTRAME, 2012).

Modelos teóricos voltados ao entendimento de mudanças de uso e cobertura da terra, a exemplo de expansão agrícola, datam do início do século XIX e se estendem por todo o século XX (BRIASSOULIS, 2000). A partir da década de 1960, esses modelos migraram para o universo digital, porém de forma rudimentar, visto que, à época, ainda não eram dotados da capacidade de lidar com a dimensão espacial.

Com o advento da computação gráfica, nos anos de 1980, surgiram refinados modelos computacionais destinados a simular essas mudanças (BATTY et al., 1997), já incorporando a dimensão espacial, de tal modo que o espaço geográfico sob análise era representado sob a forma matricial, isto é, em formato raster. A imensa maioria desses modelos, os quais possuem desdobramentos até o momento atual, repousa sobre o paradigma de autômatos celulares, que tem como premissa um sistema fechado consistindo de uma grade de células homogêneas, cujos estados (ou atributos) são discretos, e as mudanças desses estados, as quais ocorrem ao longo de passos de tempo também discretos, obedecem a regras universais, isto é, extensíveis a todo o sistema, e ancoradas no conceito de vizinhança local, isto é, de que 
inexiste ação à distância. Modelos baseados em autômatos celulares têm sido a tônica em simulações de mudanças de uso e cobertura da terra, nas quais o tipo de uso ou cobertura corresponde ao estado das células representantes da superfície geográfica em análise.

Entender como essas mudanças ocorrem, quais são as suas forças direcionadoras e, sobretudo, tentar antever essas mudanças sempre foi uma preocupação dos tomadores de decisão da esfera pública e privada. E modelos dinâmicos espaciais de mudanças de uso e cobertura da terra vêm justamente ao encontro desses anseios, pois eles podem não somente reproduzir alterações pretéritas de uso e cobertura da terra em ambiente computacional, procurando revelar o papel dos diferentes fatores responsáveis por essas mudanças, como também simular mudanças hipotéticas futuras, com base em diferentes conjeturas (cenários) e para horizontes de projeto específicos. Tais predições fornecem insumos e alternativas de estratégias para o processo de tomada de decisão, cuja importância se evidencia pelo fato de envolver o aporte de recursos materiais, financeiros, tecnológicos, institucionais e humanos (SOARES-FILHO et al., 2001)

O objetivo do trabalho foi o de aplicar e avaliar um modelo de autômatos celulares para simular mudanças de uso e cobertura da terra vinculadas à expansão agrícola no município de Campos Novos/SC, para o período de 2003 a 2012, avaliando-se o resultado retrospectivo de 2007 com base nos dados oriundos do Censo Agropecuário (IBGE, 2012), e o resultado retrospectivo de 2008 com base na imagem Landsat 5-TM classificada da área de estudo.

O modelo foi executado na plataforma Dinamica EGO, a qual opera a partir da vizinhança de Moore (janela 3x3) e apresenta a vantagem de utilizar algoritmos estocásticos de alocação de mudanças de uso e cobertura da terra. Essa plataforma de modelagem é de domínio público e foi desenvolvida pelo Centro de Sensoriamento Remoto da Universidade Federal de Minas Gerais (SOARES-FILHO et al., 2002).

\section{Material e Métodos}

\section{Área de Estudo}

Todas as informações apresentadas nesta seção, relativas à caracterização geográfica do município em estudo, foram extraídas do Arquivo Histórico Municipal Deputado Waldemar Rupp, disponibilizado em Prefeitura Municipal de Campos Novos (2010), e no trabalho de Pandolfo et al. (2002). 
O município de Campos Novos localiza-se no sudoeste catarinense (Figura 1), possui $1.850 \mathrm{~km}^{2}$, sendo que menos de $1 \%$ dessa superfície é considerada área urbana. Possui 28.447 habitantes, sendo apenas $20 \%$ residente em área rural. Com uma economia baseada essencialmente na agropecuária, apresenta grandes áreas de cultura intensiva, tais como soja e trigo, sendo responsável por uma das maiores arrecadações de ICMS no setor agropecuário do estado de SC (PREFEITURA MUNICIPAL DE CAMPOS NOVOS, 2010). A maior taxa de ocupação por monoculturas (soja e trigo, principalmente) no estado de Santa Catarina encontra-se no município de Campos Novos, conhecido como "capital catarinense da soja", propiciando boa indicação para um estudo de caso.

Segundo Pandolfo et al. (2002), a zona agroecológica em que este município está inserido, é classificada como clima temperado, constantemente úmido, sem estação seca, com verão fresco (mesotérmico brando).

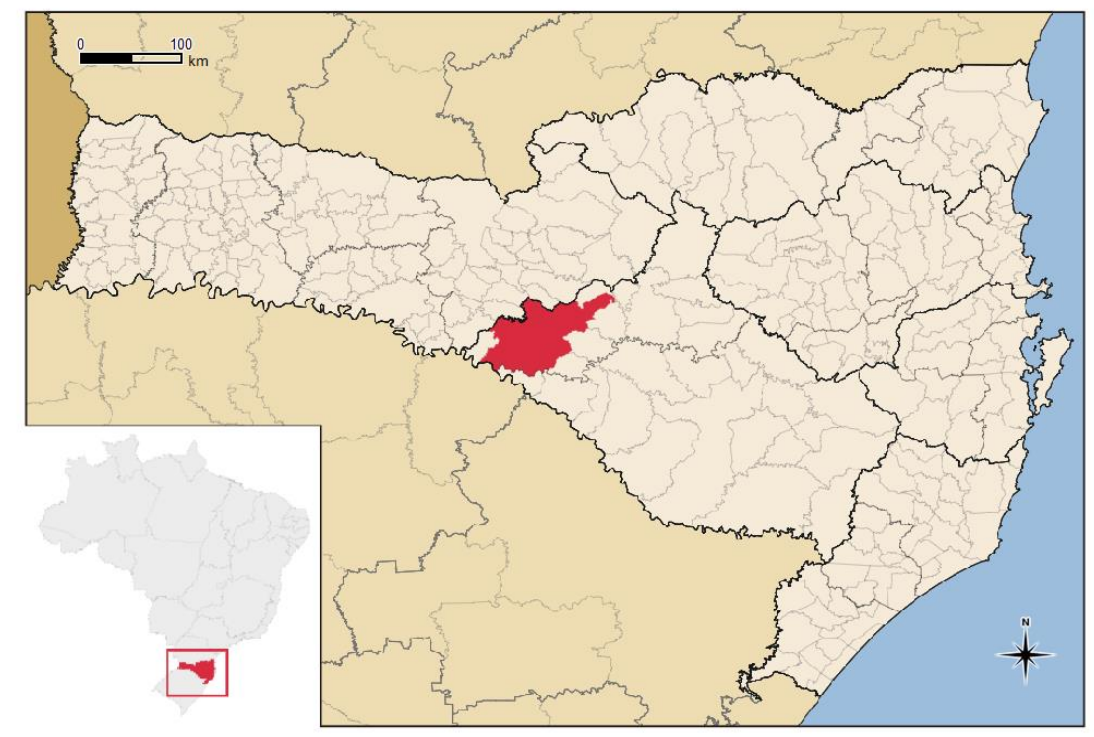

Figura 1. Localização da área de estudo em relação ao Brasil (detalhe no canto inferior esquerdo) e ao estado de Santa Catarina (centro).

Fonte: Wikipedia (2012).

A temperatura média pode variar de 15,8 a $17,9^{\circ} \mathrm{C}$. A temperatura normal das máximas varia de 22,3 a $25,8^{\circ} \mathrm{C}$ e das mínimas de 10,8 a $12,9^{\circ} \mathrm{C}$. O total de precipitação anual varia entre $1.460 \mathrm{~mm}$ e $1.820 \mathrm{~mm}$, com o total anual de dias de chuva definido entre $129 \mathrm{e}$ 144 dias. A umidade relativa do ar pode variar de 76,3 a 77,7\%. Podem ocorrer, em termos normais, de 12 a 22 geadas por ano. Os valores de horas de frio abaixo ou iguais a $7,2^{\circ} \mathrm{C}$ variam de 437 a 642 horas acumuladas por ano (PANDOLFO et al., 2002). 
O município apresenta solos profundos, bem drenados e com condições físicas favoráveis ao desenvolvimento radicular. Quando ocorrem em relevo suave ondulado, não oferecem maiores problemas ao uso de máquinas e implementos agrícolas, e a sua susceptibilidade à erosão é apenas moderada. Quando ocorre em relevo ondulado a fortemente ondulado, apresentam maior suscetibilidade à erosão e maiores impedimentos à mecanização, especialmente quando associados à presença de cambissolos, que podem apresentar pedras em seu perfil. Quimicamente, porém, são solos muito ácidos, com elevada toxidez, causada pelo alumínio trocável, e com reduzida reserva de nutrientes, especialmente nos horizontes subsuperficiais. Porém, desde que manejados adequadamente, tornam-se aptos tanto para cultivos anuais como para usos menos intensivos, entre os quais a fruticultura de clima temperado, a pastagem e o reflorestamento (PANDOLFO et al., 2002).

\section{Procedimentos}

\section{Preparação dos dados, seleção das variáveis explicativas e geração dos cubos de variáveis}

A Figura 2 ilustra o desenvolvimento metodológico associado a esta etapa preliminar de preparação dos dados e geração dos cubos de variáveis direcionadoras ou explicativas. Foram gerados mapas de uso e cobertura da terra referentes aos anos de 2002 (mapa inicial) e 2008 (mapa final), a partir de imagens Landsat 5-TM (cena 221/79), inverno e verão, com resolução espacial de $30 \mathrm{~m}$ e com as bandas originais nas faixas do visível (bandas 1, 2 e 3), infravermelho próximo (banda 4) e infravermelho médio (bandas 5 e 7). Tais imagens foram georreferenciadas empregando-se o método de reamostragem por vizinho mais próximo, a partir das imagens Geocover, originalmente fornecidas em projeção UTM e datum horizontal WGS84, cuja raiz quadrada do erro médio quadrático (root mean square error - RMSE) é reportada como sendo $50 \mathrm{~m}$ (UMD, 2017).

Essas imagens foram classificadas por meio de uma abordagem baseada em objeto no software Definiens Developer 7.0, utilizando-se o classificador por lógica nebulosa, a partir de funções booleanas e contínuas, complementada por posterior edição manual. A validação se deu por meio de pontos aleatórios estratificados por área das classes, adotando-se como dado de referência temática as imagens de melhor resolução espacial disponíveis no Google Earth (GOOGLE INC., 2009), associadas à análise visual de imagens por fotointérprete especialista. Cabe salientar que o o Google Earth foi utilizado apenas como apoio para avaliação temática (e não posicional), a fim de dirimir dúvidas dos fotointérpretes, tendo em 
vista sua resolução espacial mais refinada que a do Landsat, bem como sua capacidade em fornecer dados passados por meio do comando "Séries Históricas", informação de grande valia para o período de análise deste estudo, que se iniciou em 2002.

Em relação à preparação dos mapas para posterior processamento, padronizou-se a classe de cobertura da terra corpos d’água em ambas as datas, pelo motivo de este experimento não se propor a quantificar mudanças relacionadas a esta classe. As classes mapeadas, conforme a classificação proposta pelo IBGE (2006), foram: corpos d'água; campos nativos; florestas nativas; florestas exóticas; agricultura intensiva; agricultura familiar; áreas urbanizadas.

Ximenes et al. (2008) salientam que a escolha adequada das variáveis explicativas é determinante para o sucesso do uso de modelos, pois através de suas relações com a variável dependente são definidas as células com maior ou menor probabilidade de transição de uso e/ou cobertura da terra. As variáveis explicativas selecionadas para o fenômeno a ser modelado, i.e., mudanças de uso e cobertura da terra em Campos Novos, SC, de 2002 a 2008, foram (Figura 2): altimetria, declividade, solos, hidrografia e estradas principais e secundárias.

A carta de solos (EMBRAPA, 2005) foi rasterizada (convertida em formato matricial), e as cartas de hidrografia e estradas (IBGE, 2011) foram convertidas em grades de distâncias, todas com pixel de $30 \mathrm{~m}$. Após toda a conversão dos dados em formato matricial, foi padronizado o número de linhas e colunas de todos os insumos utilizados. As variáveis altimetria e declividade (INPE, 2009), juntamente com a variável solos, foram agrupadas em um único arquivo (cubo de variáveis categóricas e estáticas). As variáveis estáticas contínuas (que são aquelas continuamente recalculadas a cada passo de tempo do modelo) selecionadas para as simulações de mudanças de uso e cobertura foram a distância aos rios, distância a estradas principais e distância a estradas secundárias (Figura 2). Uma discussão acerca de como a mudança de uso e cobertura da terra é influenciada encontra-se na seção de Resultados. 


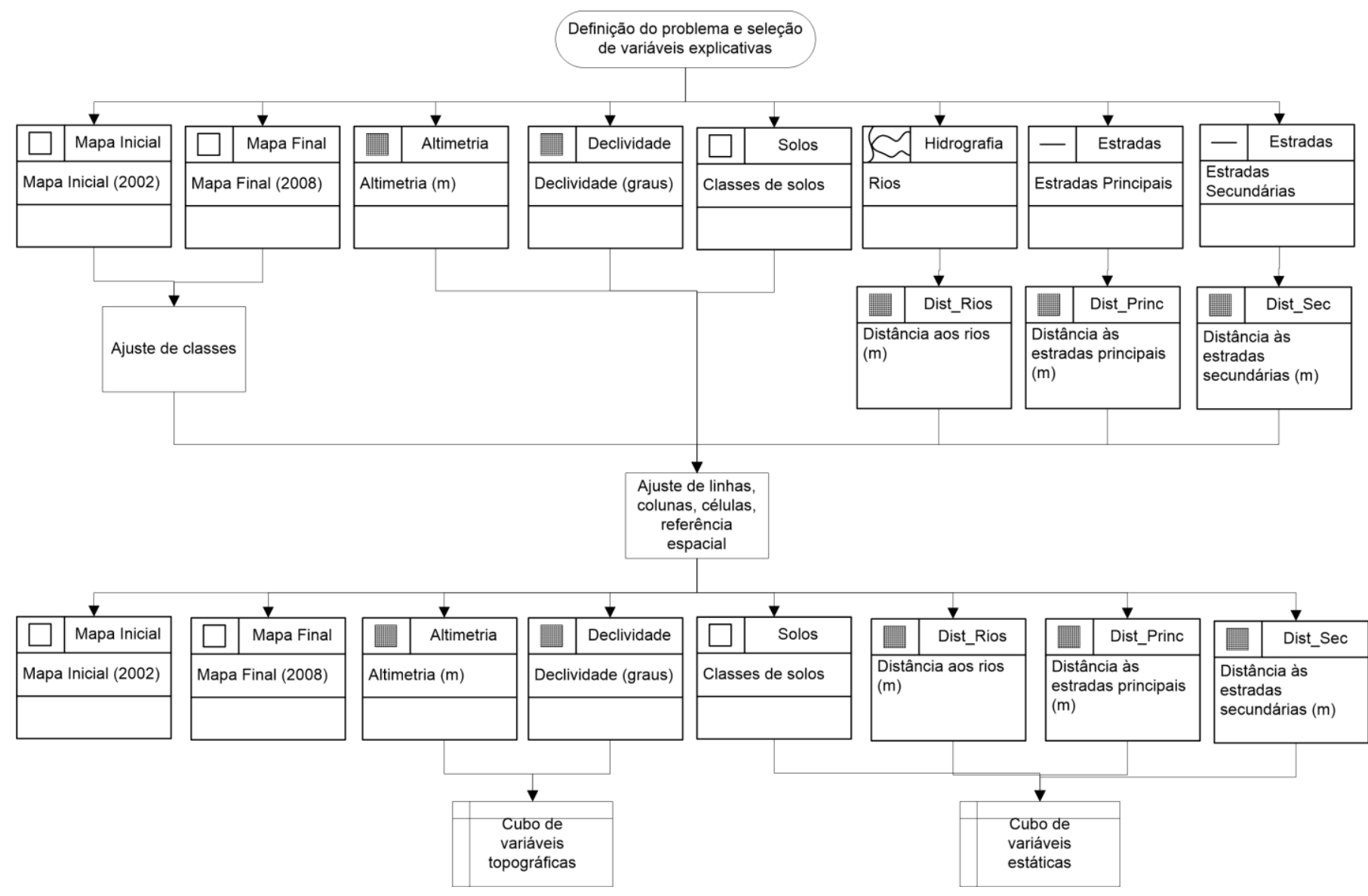

Figura 2. Fluxograma metodológico associado à preparação dos dados, seleção das variáveis explicativas e geração dos cubos de variáveis.

\section{Geração do mapa de mudança e das matrizes de transição por meio de tabulação cruzada}

Utilizando-se os mapas de uso e cobertura da terra, foram gerados um mapa de mudanças e uma matriz de tabulação cruzada, visando auxiliar nas análises preliminares das mudanças ocorridas entre os anos de 2002 e 2008. O cálculo das probabilidades globais de transição refere-se ao total de mudanças para cada tipo de transição de uso e cobertura da terra em certo período de simulação, sem levar em consideração as particularidades espaciais locais, que são aquelas pertencentes a cada célula da área de estudo em termos de características do sítio físico ou de infraestrutura.

Com base nos mapas de uso e cobertura da terra, foram calculadas taxas de transição em um passo simples, ou seja, do período completo (6 anos) e em passos múltiplos, correspondente a cada ano, derivada de uma matriz ergódica. A Figura 3 apresenta as etapas metodológicas para a geração, por meio de tabulação cruzada, do mapa de mudança e das matrizes de transição de passo simples ou único (single) e de passos anuais (multiple). 


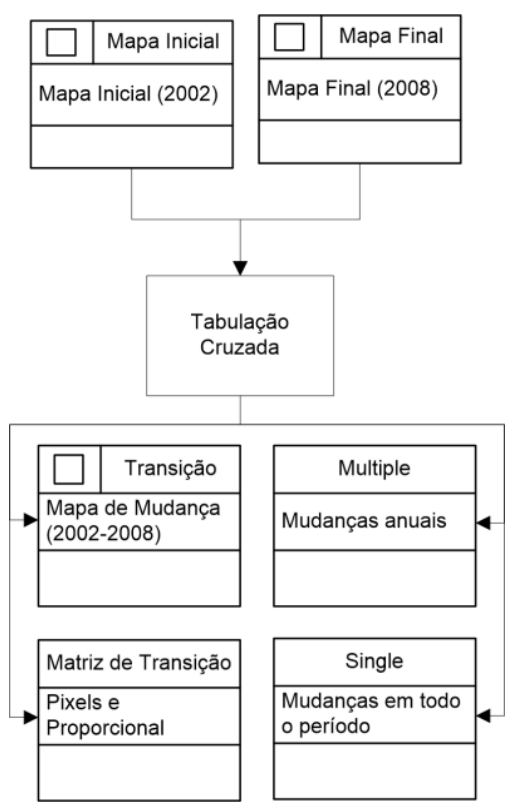

Figura 3. Fluxograma metodológico associado à geração do mapa de mudança e das matrizes de transição por meio de uma operação de tabulação cruzada.

Para análise das transições, foram convencionados os seguintes processos:

- Degradação - Redução de ambientes nativos, ou seja, qualquer mudança que reduza a área de campos e florestas nativos;

- Regeneração - Aumento de ambientes nativos, ou seja, qualquer mudança que aumente a área de campos e florestas nativos;

- Concentração - Aumento de agricultura intensiva e de florestas exóticas, em detrimento de agricultura familiar;

- Distribuição - Aumento de agricultura familiar em detrimento de agricultura intensiva e florestas exóticas;

- Horizontalização - Mudanças entre agricultura intensiva e florestas exóticas;

- Urbanização - Aumento de áreas urbanizadas em detrimento de ambientes produtivos, ou seja, florestas exóticas e agricultura (intensiva e familiar).

\section{Determinação dos intervalos das variáveis contínuas para cálculo dos pesos de evidência}

O método de pesos de evidência foi adotado para cálculo das probabilidades locais de transição de uso e cobertura da terra, isto é, das probabilidades de mudança em cada célula da área de estudo, considerando suas características físicas. Este método baseia-se no Teorema de Bayes ou da Probabilidade Condicional e opera apenas com variáveis discretas, isto é, categóricas. Para tanto, é necessário a categorização das variáveis contínuas, sejam elas estáticas, tais como distâncias a certos alvos, ou dinâmicas, como as distâncias a classes de uso e cobertura da terra. As variáveis dinâmicas, diferentemente das estáticas, são aquelas que se 
alteram a cada passo de tempo da simulação, e por isto, são recalculadas continuamente durante a execução do modelo. Os pesos são calculados para cada transição, e por este motivo, faz-se necessário o uso dos mapas de uso e cobertura da terra inicial e final, pois a partir do cruzamento entre os mesmos é que são identificadas as transições observadas e suas respectivas áreas de ocorrência. Tais pesos são empregados para produzir os mapas de probabilidade de transição, utilizados nas simulações. Cada transição produz um mapa de probabilidades locais separadamente.

Como a determinação dos pesos das variáveis explicativas pressupõe a independência de eventos (Teorema de Bayes), verificou-se a sua existência através dos testes de associação espacial, considerando-se os seguintes índices: Crammer (V) e o Joint Information Uncertainty (JIU), ou Índice de Incerteza da Informação Conjunta. Estes índices operam com valores reais e percentuais, respectivamente, e avaliam a associação ou dependência espacial entre pares de variáveis utilizadas para explicar uma mesma transição de uso e cobertura da terra. De acordo com Bonham-Carter (1994), valores abaixo de 0,5 sugerem uma tênue dependência espacial entre as variáveis consideradas. Desta forma, adotou-se o limiar de 0,5 para se decidir sobre a inclusão (V ou JIU $<0,5$ ) ou exclusão (V ou JIU $\geq 0,5$ ) de variáveis no modelo.

A Figura 4 ilustra os procedimentos envolvidos no cálculo dos pesos de evidência (coeficientes) das variáveis explicativas e na determinação da correlação (associação ou dependência espacial) entre pares de variáveis destinadas a explicar uma mesma transição, necessárias à seleção definitiva de variáveis que integrarão o modelo de simulação.

Os mapas inicial e final são submetidos a uma operação de tabulação cruzada, gerando mapas de mudança, nos quais identificam-se as áreas de transição. Na sequência, por meio de nova operação de tabulação cruzada dos mapas de mudança com as respectivas variáveis selecionadas para explicar cada uma das transições, serão identificados os totais de células de transição que recaem sobre as diferentes faixas discretizadas das variáveis topográficas e de distância, permitindo assim o cálculo do peso positivo de evidência, conforme Bonham-Carter (1994). 


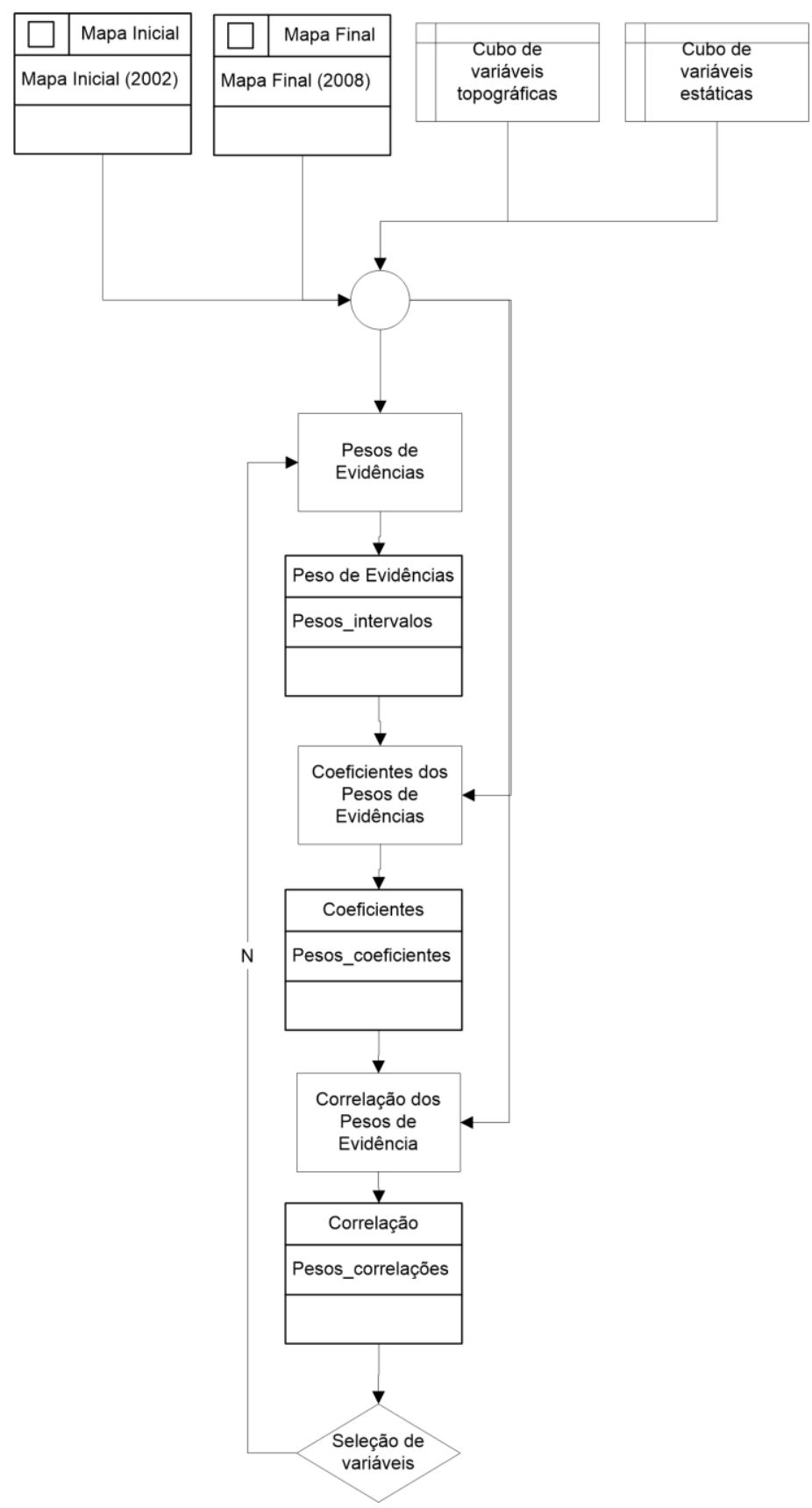

Figura 4. Fluxograma metodológico associado ao cálculo dos pesos de evidência (coeficientes) das variáveis explicativas e à determinação da correlação entre pares de variáveis, como requisito para a seleção definitiva de variáveis do modelo de simulação.

Para estimar a correlação entre variáveis, isto é, para se calcular os índices V e JIU conforme anteriormente explicado, operações de tabulação cruzada são realizadas entre todas as combinações possíveis de pares de variáveis utilizadas para explicar cada uma das transições de uso e cobertura da terra, uma vez que ambos os índices dependem de valores extraídos de matrizes de tabulação cruzada. 


\section{Definição dos parâmetros patcher e expander}

Estes dois parâmetros referem-se aos algoritmos ou funções de transição, responsáveis pela alocação de mudanças de uso e cobertura da terra no modelo. A função expander responde pela expansão de manchas previamente existentes de certa classe de uso ou cobertura da terra. A função patcher, por sua vez, destina-se a gerar novas manchas, através de um mecanismo de difusão, i.e., de constituição de sementes que darão origem a novas manchas de uso ou cobertura da terra em meio à paisagem (SOARES-FILHO et al., 2002).

Além das proporções destinadas a mudanças tanto por expansão quanto por difusão, que juntas devem somar 1, são necessários os seguintes parâmetros: área média e variância da área das manchas de mudança, fornecidas em hectares, separadamente para as transições a serem executadas por patcher e expander. Os parâmetros de área média e variância de área de manchas, obtidos por meio de consultas espaciais e cálculos estatísticos realizados a partir dos mapas de mudança vetorizados, são necessários para reproduzir nas simulações a morfologia (ou padrão geométrico e de distribuição espacial) das áreas de transição de uso e cobertura da terra de forma condizente àquela observada no mapa real da área de estudo, no tempo final do período de simulação (2008). Outro parâmetro, denominado índice de isometria de manchas, também é necessário para a calibração do modelo.

Segundo Ximenes et al. (2008), “este índice representa um valor numérico, o qual é multiplicado pelo valor de probabilidade das oito células da janela de vizinhança $3 \times 3$ pixels, utilizada pelos algoritmos patcher e expander, antes da aplicação da regra de transição. Quanto mais elevado é o valor do índice, mais compactas serão as manchas produzidas pelas funções de transição, e, de forma oposta, quanto mais próximo de zero, mais fragmentadas serão as manchas".

Neste trabalho, adotou-se o valor de 1,5 para o índice de isometria em todos os casos. Uma vez definidos os parâmetros de proporção de patcher e expander (em valores percentuais), de área média e variância de área de manchas (em hectares), bem como do índice de isometria de manchas (valor adimensional), tem início a execução do modelo, que produzirá como saída mapas anuais de probabilidades para cada transição observada e, finalmente, as simulações anuais de mudanças de uso e cobertura da terra em Campos Novos (Figura 5). As simulações são produzidas com base na iteração dos algoritmos patcher e expander sobre os mapas de probabilidade de transição. 


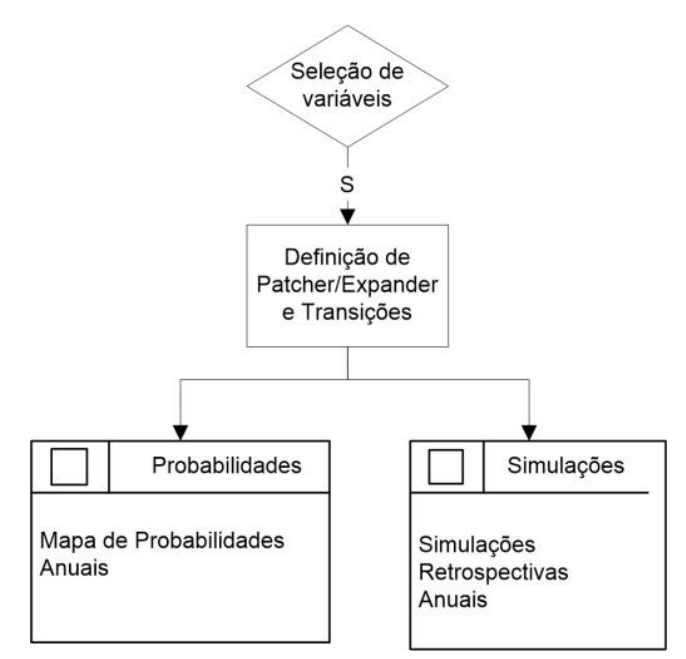

Figura 5. Fluxograma metodológico associado à definição dos parâmetros de patcher e expander, necessários à execução do modelo, que produzirá como saída mapas anuais de probabilidades para cada transição observada e as simulações anuais de mudanças de uso e cobertura da terra.

Visando obter a melhor configuração, foram testados cinco tratamentos, com os seguintes parâmetros :

1. $\quad 100 \%$ patcher $\mathrm{p} /$ todas as transições;

2. $\quad 100 \%$ expander $\mathrm{p} /$ todas as transições;

3. $\quad 50 \%$ patcher; $50 \%$ expander $\mathrm{p} /$ todas as transições;

4. $100 \%$ patcher p/ Degradação, Regeneração, Horizontalização, Distribuição \& $100 \%$ expander $\mathrm{p} /$ Concentração, Urbanização;

5. Melhor dos tratamentos com aumento de 10 vezes no tamanho médio das áreas de expansão agrícola.

\section{Validação do modelo e geração de cenários prospectivos}

Por fim, foram comparadas as simulações produzidas pelo modelo com o mapa final real (referência). O método aplicado foi o desenvolvido por Hagen (2003), baseado no conceito de "fuzziness of location" (incerteza de localização), no qual a representação de uma célula é influenciada por ela mesma, e, em menor magnitude, pelas células na sua vizinhança. Trata-se de um teste de comparação de similaridade fuzzy entre dois mapas-diferença, sendo o primeiro resultante da subtração entre o mapa final real e o mapa inicial real, e o segundo, da subtração entre o mapa final simulado e o mapa inicial real. Neste caso, empregou-se uma função de decaimento constante calculada a partir dos seguintes tamanhos de janelas: 1x1, $3 \times 3,5 \times 5,7 \times 7$ e $9 \times 9$ pixels. 
Como o índice de similaridade fuzzy é calculado de forma recíproca, isto é, em um primeiro momento compara-se o primeiro mapa-diferença ao segundo mapa-diferença, e em uma etapa subsequente, efetua-se a comparação inversa, são fornecidos dois valores numéricos para este índice, bem como dois mapas de concordância, que sinalizam ajustes e incongruências das simulações. Assim, têm-se, via de regra, um índice mínimo (minimum) e um máximo (maximum), bem como uma mapa de concordância mínima (minimum) e um de concordância máxima (maximum) (Figura 6). Utilizando-se o melhor tratamento avaliado, tanto quantitativamente (por meio do índice de similaridade fuzzy) quanto visualmente, foram gerados prognósticos (simulações prospectivas) com base em cenários estacionários (em que se mantiveram as mesmas taxas de transição observadas de 2002 a 2008) para o período compreendido entre os anos de 2009 e 2012. Estas etapas metodológicas encontram-se sumariadas na Figura 6.

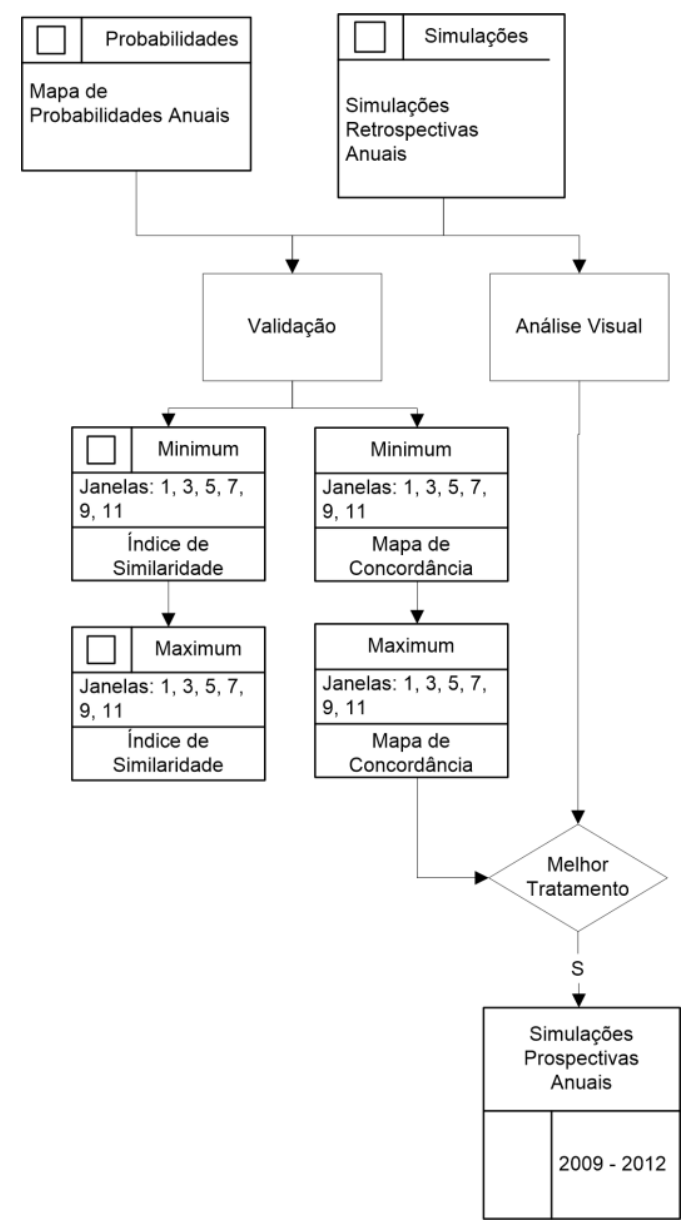

Figura 6. Fluxograma metodológico associado à validação estatística do modelo e à geração de cenários prospectivos. 
Visando complementar a avaliação, comparou-se a simulação pretérita referente ao ano de 2007 com os dados do Censo Agropecuário de 2006/2007 (IBGE, 2012). Embora o Censo tenha caráter declaratório, ele se constitui em fonte de dados oficiais do Governo Federal, é de livre acesso, e no caso particular do ano de 2007, fornece dados temporalmente coincidentes com uma das simulações intermediárias retrospectivas, para a qual não se dispunha de imagem classificada. Cabe ressaltar que esses dados foram utilizados apenas complementarmente, a fim de avaliar se tal simulação pretérita não se encontrava dissonante da realidade.

\section{Resultados}

Os mapas de cobertura e uso da terra referentes aos anos de 2002 (mapa inicial) e 2008 (mapa final) podem ser visualizados nas Figuras 7 e 8, respectivamente.

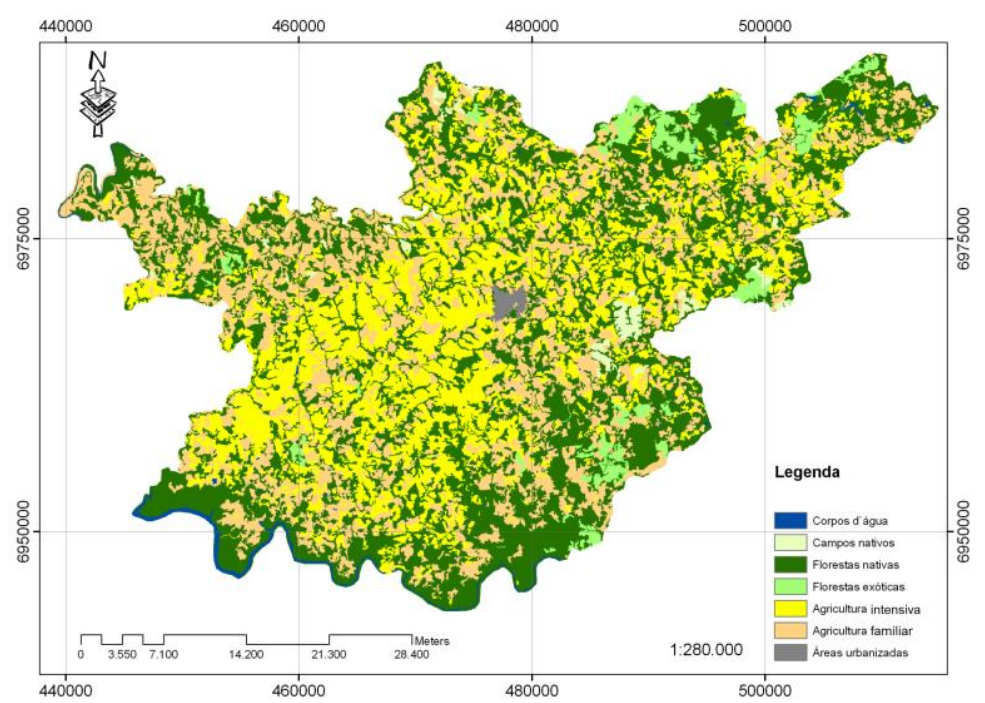

Figura 7. Mapa de uso e cobertura da terra de 2002 (mapa inicial).

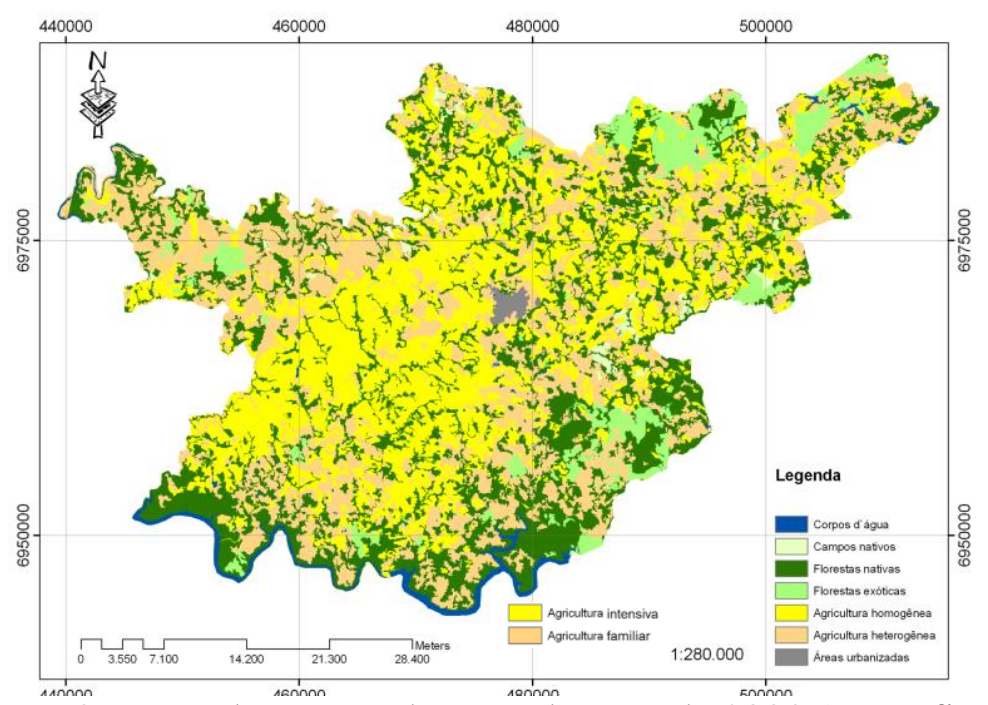

Figura 8. Mapa de uso e cobertura da terra de 2008 (mapa final). 
Através da operação de tabulação cruzada, foi gerado o mapa de mudança de uso e cobertura da terra (Figura 9), mudança esta que responde por quase $20 \%$ da área do município.

Visualmente, é possível perceber a prevalência de processos relacionados à degradação de ambientes nativos, ou seja, expansão agrícola (intensiva e familiar) em detrimentos de áreas anteriormente ocupadas com campos e florestas nativas.

Há ocorrência de regeneração - de florestas nativas em áreas anteriormente ocupadas por agricultura familiar - mas é nitidamente menor que os processos de degradação. Em relação às mudanças horizontalizadas (agricultura intensiva e florestas exóticas), há certa proporcionalidade e equilíbrio nas taxas de mudança. Processos relacionados à concentração de terra superaram ligeiramente os processos relacionados à redistribuição de terras. E processos relacionados à urbanização ocorreram em taxas baixíssimas.

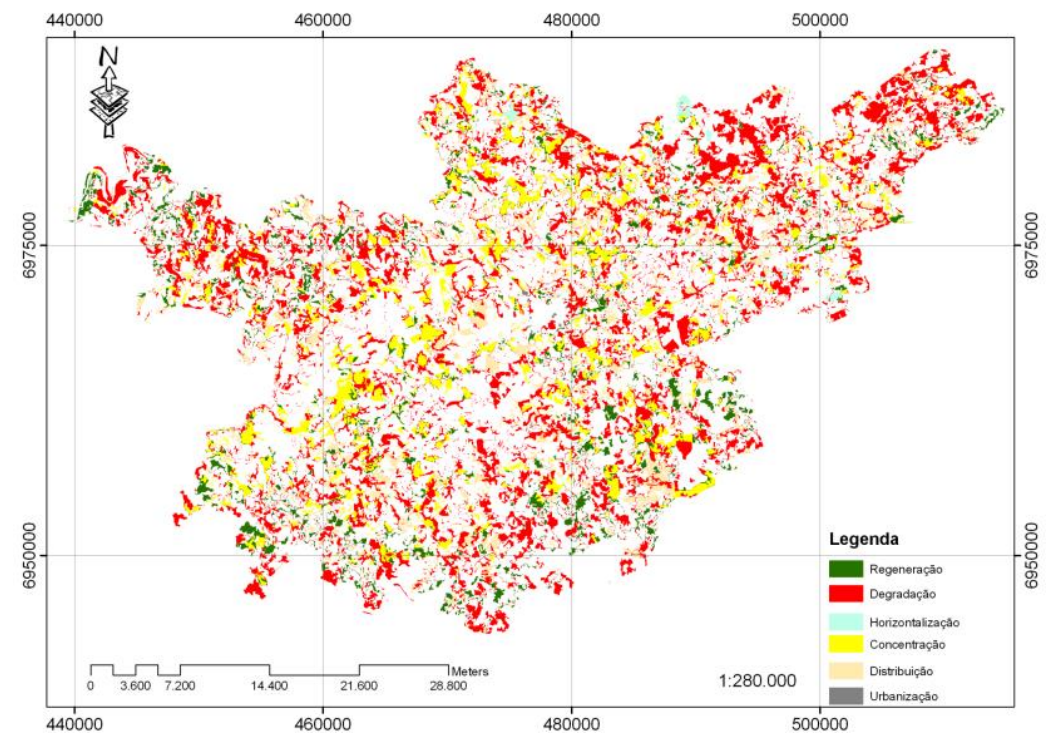

Figura 9. Mapa relativo aos processos de mudança de uso e cobertura da terra de 2002 a 2008, obtido por meio de tabulação cruzada entre os mapas reais (inicial e final) desse período.

Os resultados provenientes dos cálculos das matrizes de transição global estão expressos na Figura 10. É possível perceber que os processos relacionados à degradação somam quase metade de todas as mudanças ocorridas. É interessante notar que, apesar de a agricultura familiar ter aumentado com taxas proporcionais em relação à agricultura intensiva em 2008, esta, por sua vez, teve um maior decréscimo de área em 2002, o que explica taxas 
de concentração de terras maiores que de redistribuição. Visando calcular o saldo após o período de mudanças, foram subtraídos os decréscimos de 2002 com os acréscimos de 2008, cujos resultados podem ser visualizados na Figura 11.

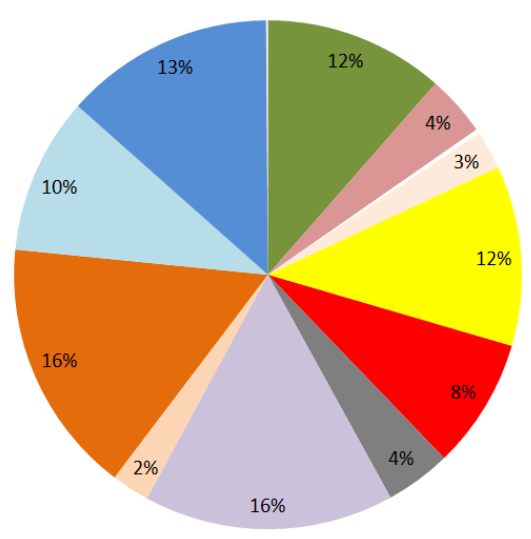

- Agricultura Familiar p/ Florestas Nativas

— Florestas Nativas p/ Florestas Exóticas

Agricultura Familiar p/ Florestas Exóticas

- Campos Nativos $\mathrm{p} /$ Agricultura Intensiva

- Florestas Nativas p/ Agricultura Intensiva

- Florestas Exóticas p/Agricultura Intensiva

- Agricultura Familiar Agricultura Intensiva

= Campos Nativos p/ Agricultura Familiar

n Florestas Nativas p/ Agricultura Familiar

- Florestas Exóticas p/Agricultura Familiar

- Agricultura Intensiva p/ Agricultura Familiar

Figura 10. Proporção das mudanças ocorridas entre as duas datas analisadas, com base nos mapas reais.

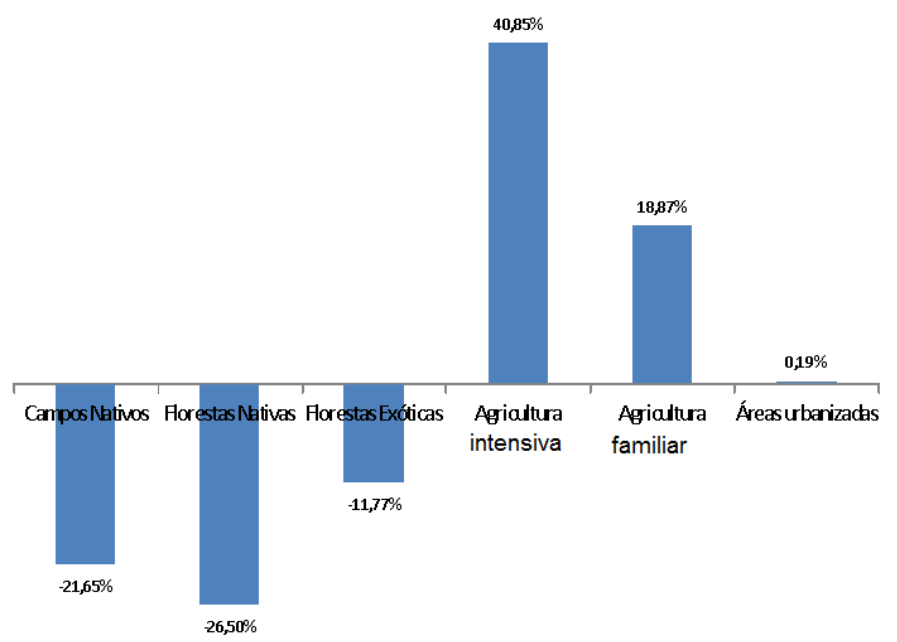

Figura 11. Balanço das mudanças ocorridas de 2002 a 2008, por classe de uso e cobertura da terra, com base nos mapas reais.

Visando verificar a independência de eventos na determinação dos pesos das variáveis explicativas, foram realizados os testes de associação ou dependência espacial - Crammer (V) e o Joint Information Uncertainty (JIU), considerados apenas os resultados com valores maiores que 0,5. As variáveis mais sensíveis ao modelo, com base nos pesos de evidências, para cada transição podem ser visualizadas no Quadro 1. 
Quadro 1. Variáveis mais sensíveis ao modelo, por transição de cobertura e uso da terra.

\begin{tabular}{|ll|}
\hline \multicolumn{1}{|c|}{ Transição } & \multicolumn{1}{c|}{ Variáveis } \\
Agricultura intensiva p/ agricultura familiar & Altimetria, declividade, solos e distância a agricultura familiar \\
Florestas nativas p/ agricultura intensiva & Altimetria, declividade e distância a estradas \\
Agricultura familiar p/ florestas nativas & Distância aos rios e distância a florestas nativas \\
Agricultura familiar p/ florestas exóticas & Distância a estradas e distância a florestas exóticas \\
Agricultura familiar p/ agricultura intensiva & $\begin{array}{l}\text { Altimetria, declividade e distância a estradas e distância a } \\
\text { agricultura intensiva }\end{array}$ \\
\hline
\end{tabular}

As variáveis selecionadas estão empiricamente relacionadas com as transições analisadas. A agricultura intensiva possui um índice de mecanização expressivo. Sendo assim, as variáveis altimetria e declividade apresentaram maior influência nas transições relacionadas a esta classe, contribuindo simultaneamente tanto na sua expansão (áreas mais planas) quanto na sua retração (áreas mais declivosas). Além disso, a distância a estradas também influenciou as simulações das transições envolvendo agricultura intensiva (correlação positiva) e florestas exóticas (correlação negativa). Isto demonstra que a agricultura intensiva é mais sensível à distância a estradas do que a silvicultura.

A variável solos teve influência para as transições envolvendo a agricultura familiar, confirmando a priorização de solos férteis e agricultáveis no uso agropecuário.

A recomposição florística, mesmo não sendo tão expressiva em área, ocorre fundamentalmente em processos de readequação das Áreas de Preservação Permanente, corroborando com a influência da variável distância aos rios, conforme também relatado por Macedo et al. (2013).

As distâncias da própria classe foram significativas em todas as transições, confirmando a predominância de processos de expansão em detrimento de processos de nucleação (ou difusão), no período considerado. Tais resultados respaldam a adoção do Tratamento 2 (100\% expander).

Após a exclusão das variáveis ruidosas (aquelas que apresentaram um único intervalo no processo de categorização, geralmente com valor nulo de peso de evidência) e consequente recálculo dos pesos, os testes de avaliação de similaridade não apresentaram quaisquer problemas. Previamente à avaliação estatística das mudanças simuladas, realizou-se avaliação visual, comparando-se o mapa simulado com o mapa final real (referência). Após a avaliação 
visual e análise estatística, foi escolhido o Tratamento 2 para gerar as simulações de 2002 a 2008, cujos resultados de validação estatística encontram-se na Tabela 1

Tabela 1. Resultados da validação estatística dos cinco tratamentos por meio do índice de similaridade fuzzy máximo com decaimento constante. O Tratamento $2^{4}$ foi escolhido.

$\begin{array}{lccccc}\text { Janela } & 1 & 2 & 3 & 4 & 5 \\ 1 \times 1 & 0,2909018 & \mathbf{0 , 3 7 8 2 4 9 3} & 0,3493186 & 0,3326641 & 0,3735066 \\ 3 \times 3 & 0,3707092 & \mathbf{0 , 4 5 7 2 6 0 9} & 0,4250523 & 0,4074729 & 0,4504648 \\ 5 \times 5 & 0,4580438 & \mathbf{0 , 5 3 0 8 4 2 4} & 0,4976763 & 0,4782830 & 0,5228515 \\ 7 \times 7 & 0,5300197 & \mathbf{0 , 5 9 3 4 0 0 3} & 0,5608518 & 0,5396768 & 0,5850746 \\ 9 \times 9 & 0,5888506 & \mathbf{0 , 6 4 5 0 6 8 1} & 0,6140391 & 0,5915330 & 0,6374922 \\ 11 \times 11 & 0,6379289 & \mathbf{0 , 6 8 8 3 2 3 9} & 0,6585575 & 0,6355067 & 0,6808551\end{array}$

Além disso, na Tabela 2 é possível verificar a concordância entre o cenário gerado para o ano de 2007 e os dados do Censo Agropecuário de 2007 (IBGE, 2012). A única discrepância significativa diz respeito à classe "Floresta Nativa". Porém, tal diferença refletese diretamente na totalização da área de uso/cobertura. Provavelmente, esta classe foi subdimensionada naquele levantamento, de maneira análoga aos resultados obtidos por Pino (2009) e Barbieri (2009), relacionados à distinção entre levantamentos declaratórios (Censo) e levantamentos objetivos (classificação de imagens de Sensoriamento Remoto).

Tabela 2. Comparação entre a simulação para o ano de 2007 e os dados levantados pelo Censo Agropecuário.

\begin{tabular}{lrr}
\multicolumn{1}{c}{ Classe } & Simulação (ha) & Censo Agropecuário (ha) \\
Agricultura & 108.424 & 106.466 \\
Floresta Plantada & 9.280 & 5.769 \\
Floresta Nativa & 55.151 & 22.107 \\
Vegetação Campestre & 1.791 & 1.966 \\
Água & 3.112 & 3.377 \\
Total & $\mathbf{1 7 7 . 7 5 8}$ & $\mathbf{1 3 9 . 6 8 5}$
\end{tabular}

As simulações anuais retrospectivas, de 2003 a 2008, encontram-se respectivamente nas Figuras 12 a 17, e as simulações anuais prospectivas de 2009 a 2012, baseadas em cenários estacionários, apresentam-se nas Figuras 18 a 21, respectivamente. 


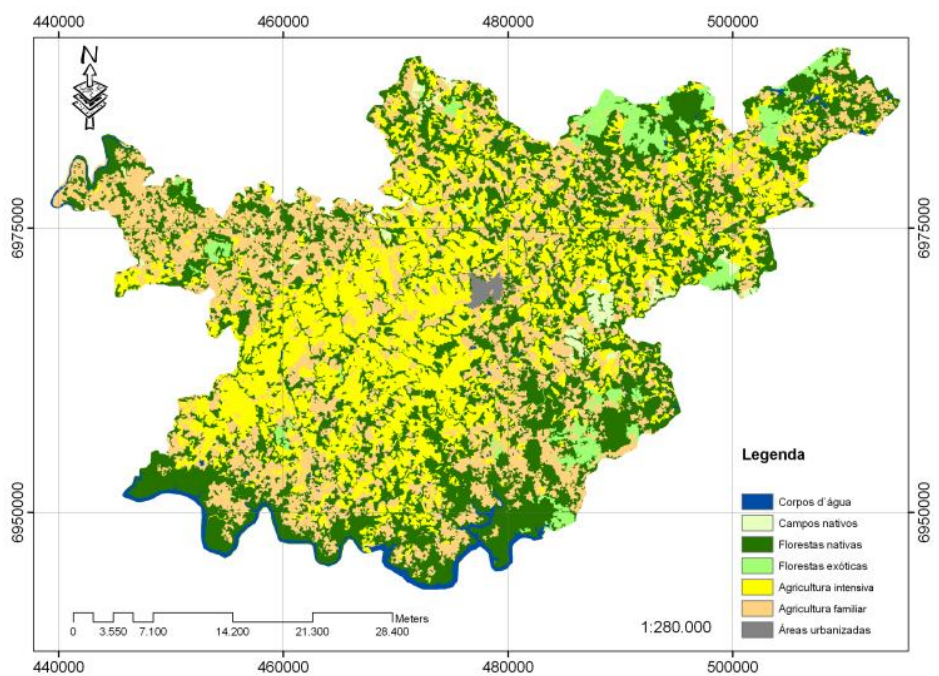

Figura 12. Simulação anual retrospectiva para o ano de 2003.

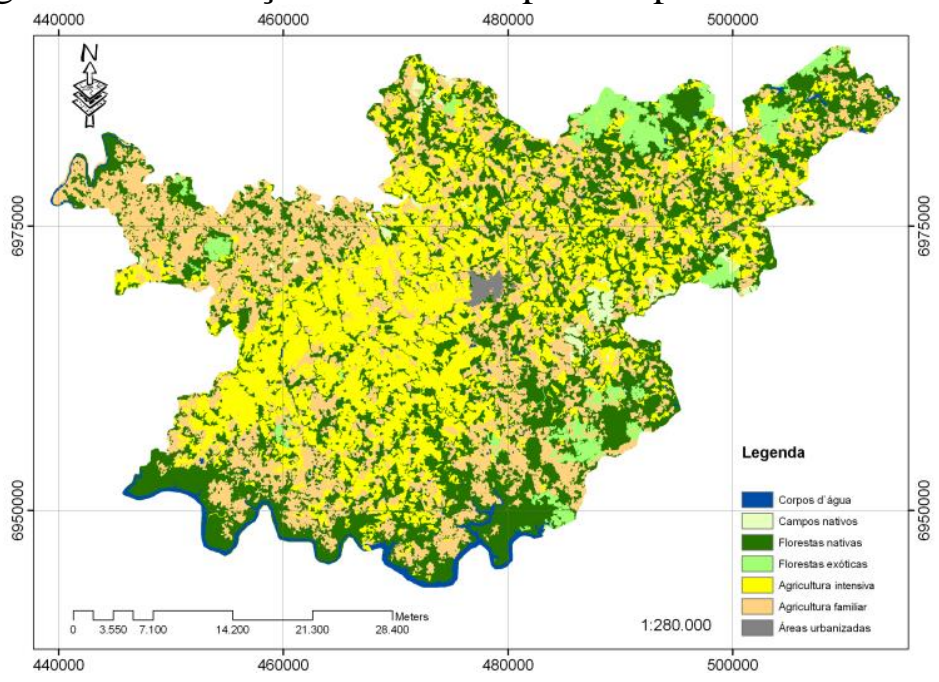

Figura 13. Simulação anual retrospectiva para o ano de 2004.

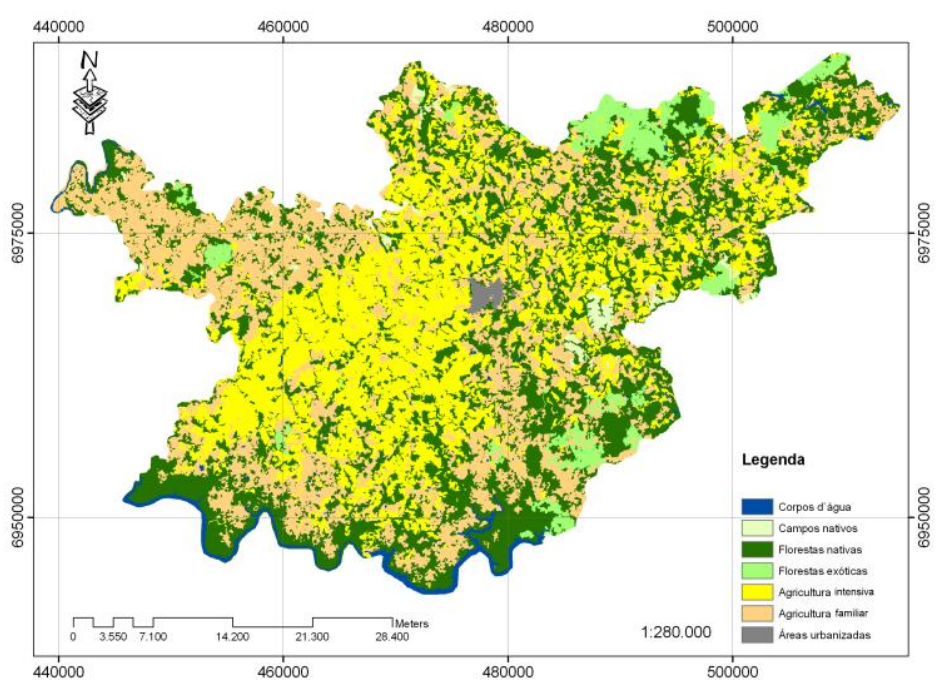


Figura 14. Simulação anual retrospectiva para o ano de 2005.

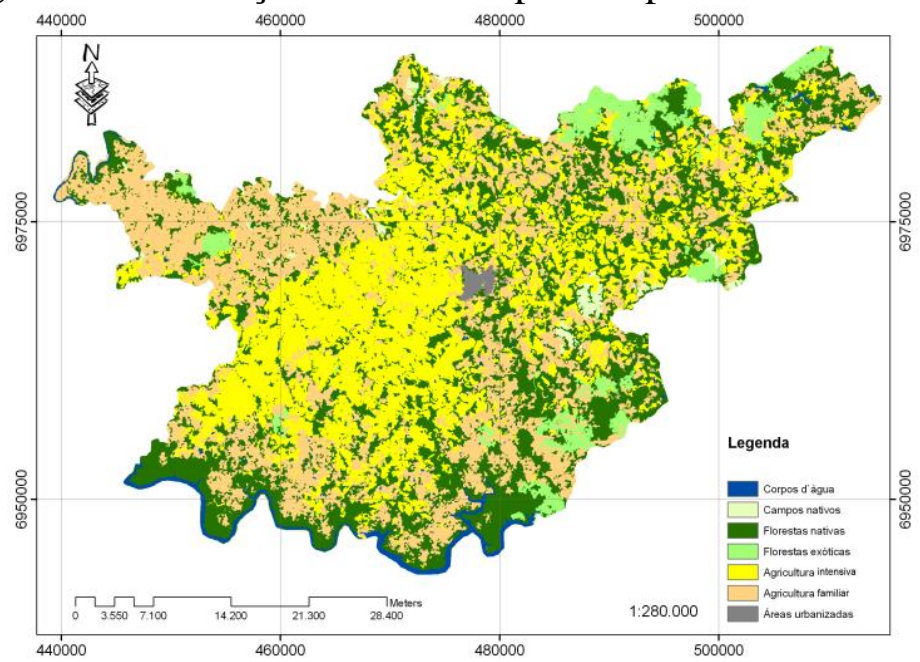

Figura 15. Simulação anual retrospectiva para o ano de 2006.

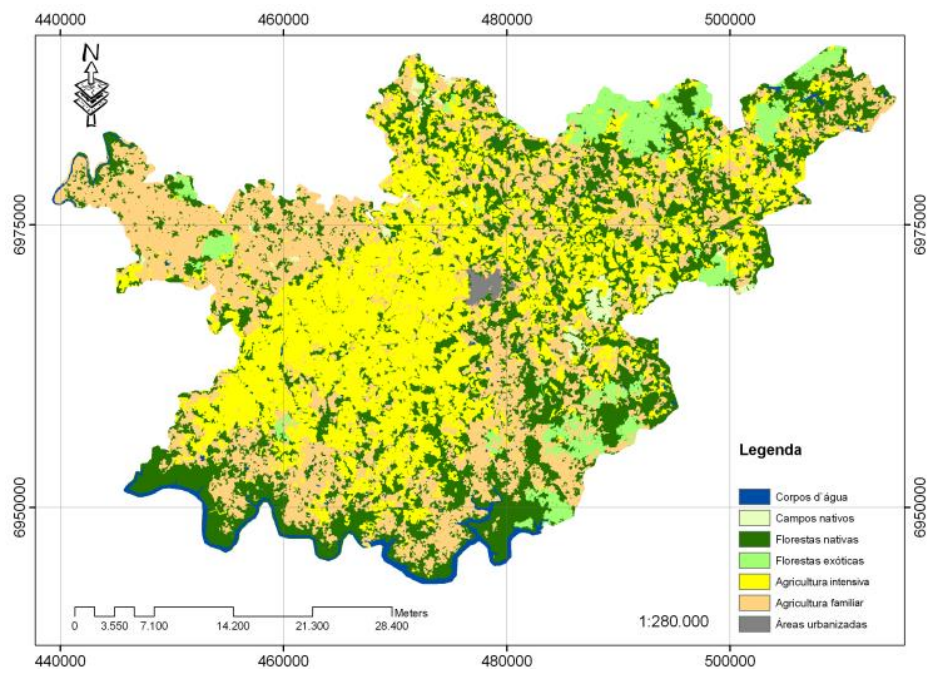

Figura 16. Simulação anual retrospectiva para o ano de 2007.

As simulações de 2003 a 2007 revelam, conforme anteriormente exposto, uma progressiva diminuição de florestas nativas, sobretudo daquelas que se encontram em meio a manchas de agricultura intensiva. As florestas exóticas também se mostraram em declínio, porém em menor intensidade.

A regeneração ou recomposição florística ocorre principalmente em locais próximos às grandes manchas de florestas nativas e, de forma prevalente, em processos de readequação das áreas de preservação permanente. A agricultura intensiva apresentou mais que o dobro do crescimento da agricultura familiar, apresentando um padrão de aglutinação espacial, ocupando em grande parte áreas anteriormente destinadas à agricultura familiar. As áreas urbanas ficaram praticamente estáveis durante esse período. 


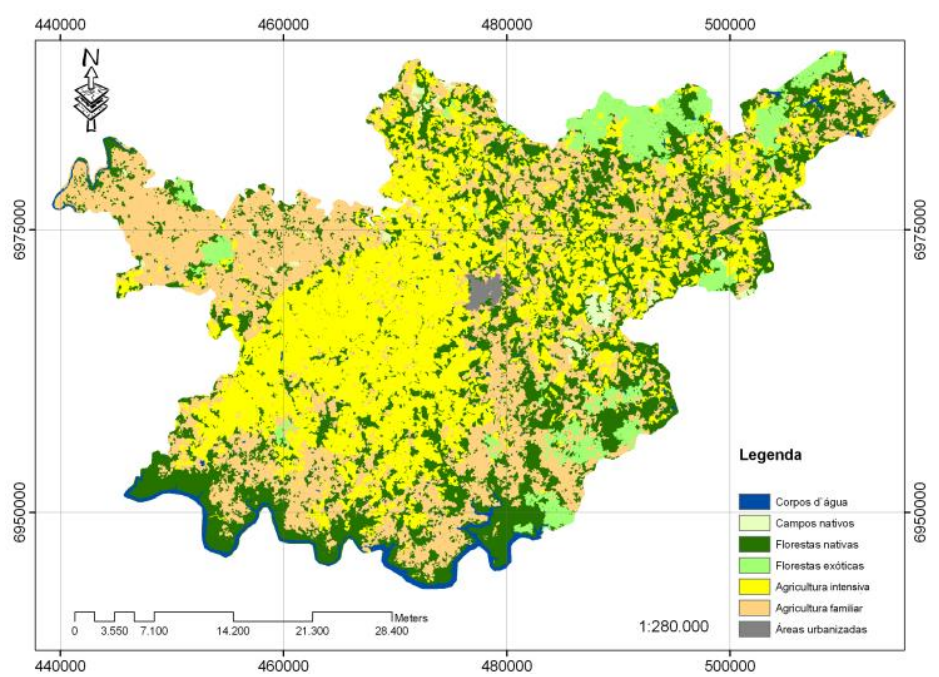

Figura 17. Simulação anual retrospectiva para o ano de 2008.

A simulação retrospectiva de 2008 (Figura 17) apresenta, segundo previamente afirmado, similaridade com o mapa real de 2008 (Figura 8). Algumas omissões ocorreram no que tange a áreas de florestas nativas ao longo de cursos d’água (áreas de preservação permanente), bem como de pequenas manchas de florestas exóticas a noroeste, sul e sudoeste do município de Campos Novos, além de áreas de agricultura familiar na porção central do município. De modo geral, o padrão de distribuição espacial da agricultura intensiva foi bem modelado.

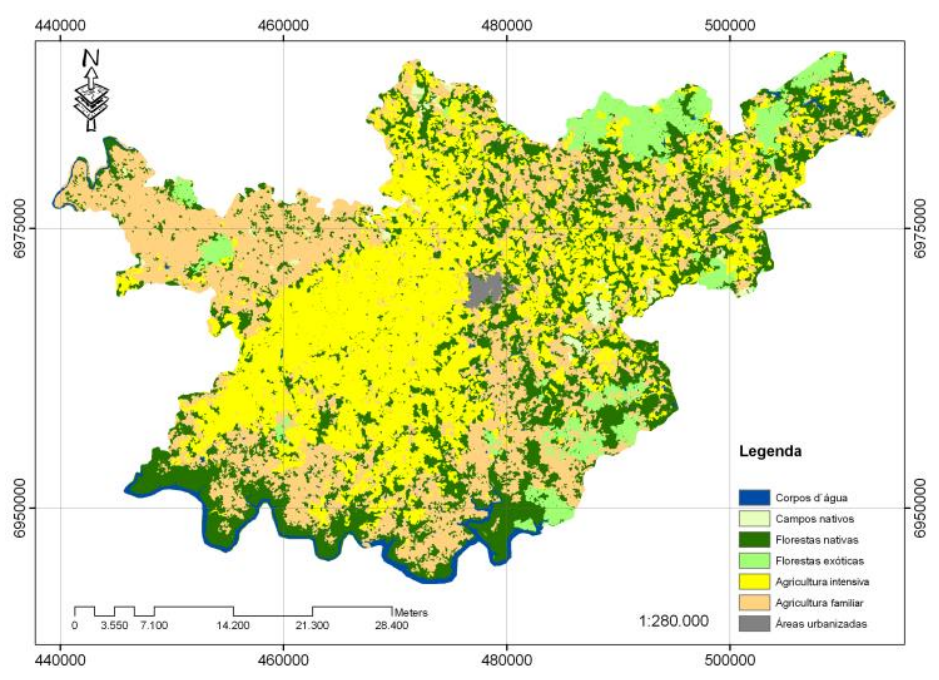

Figura 18. Simulação anual prospectiva para o ano de 2009. 


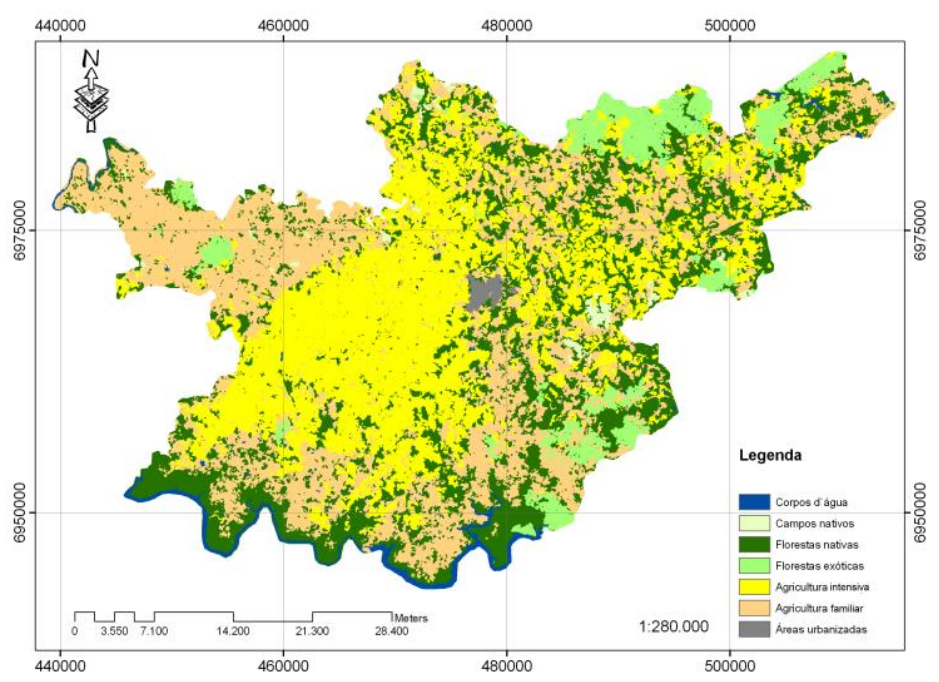

Figura 19. Simulação anual prospectiva para o ano de 2010.

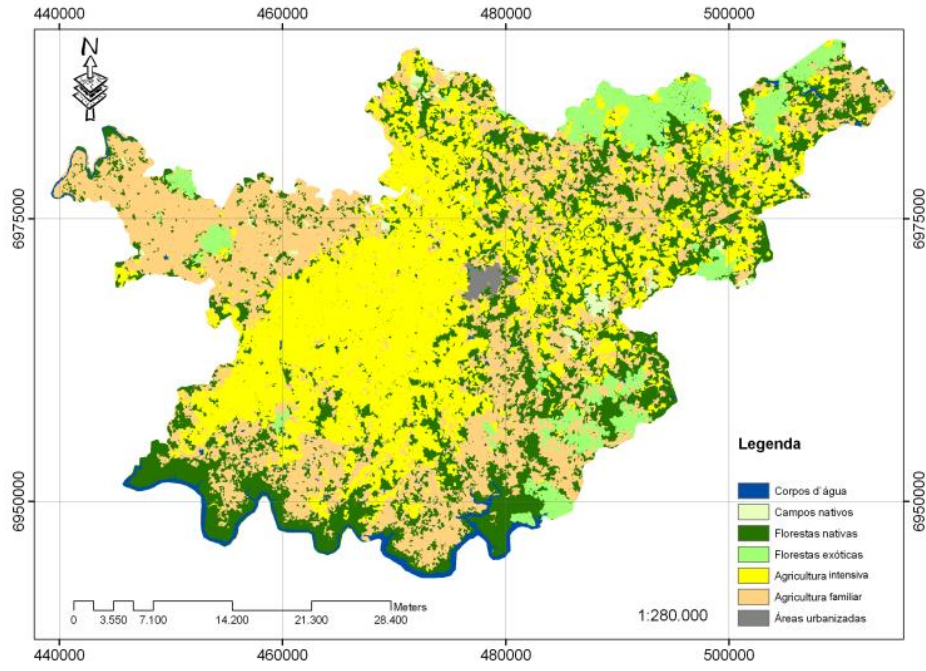

Figura 20. Simulação anual prospectiva para o ano de 2011.

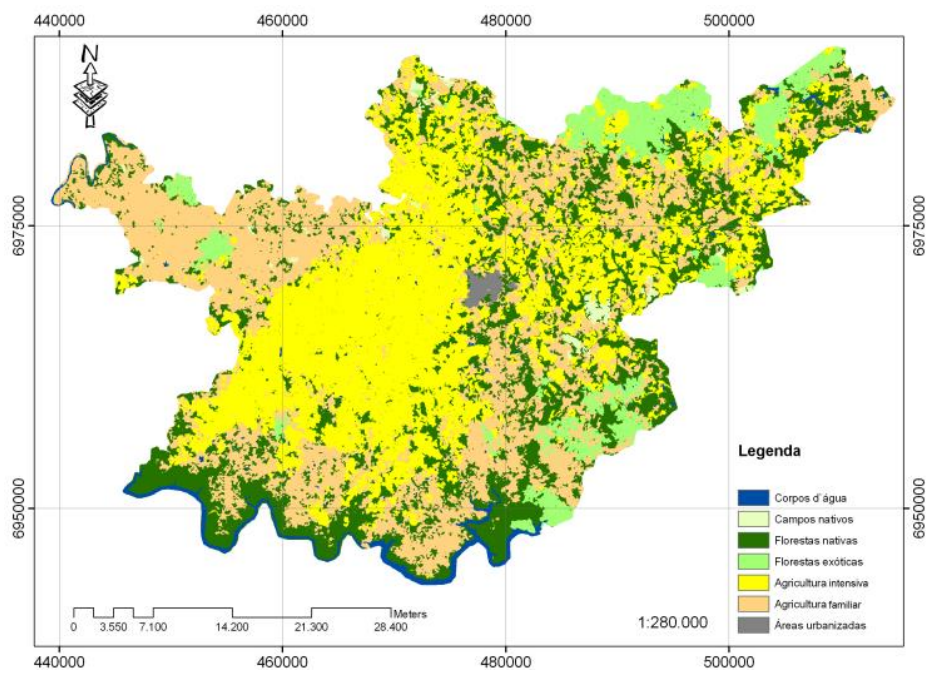

Figura 21. Simulação anual prospectiva para o ano de 2012. 
As simulações prospectivas apontam para a manutenção das tendências de mudança observadas no período de 2002 a 2008, com crescimento urbano ínfimo, supressão de florestas e campos nativos e, em menor escala, de florestas exóticas, aumento contido das áreas de agricultura familiar e densificação da agricultura intensiva.

\section{Considerações Finais}

\section{Problema Empírico}

Campos Novos mantém sua característica agrícola, sem apresentar grandes mudanças relacionadas à urbanização ou alteração de sua matriz produtiva. Houve expansão agrícola durante o período analisado, em detrimento de ambientes nativos, tais como matas e campos serranos. Além da expansão agrícola, houve aumento na concentração fundiária, ou seja, aumento de agricultura intensiva em relação à agricultura familiar.

\section{Questões técnicas}

O mapa de mudanças, gerado por meio da tabulação cruzada, e a respectiva matriz de transição foram extremamente úteis para a o diagnóstico e análise do problema abordado. $\mathrm{O}$ método de pesos de evidência possibilitou analisar quais variáveis são as mais importantes em cada transição. Tal fato tem papel fundamental no entendimento do processo de mudança de uso e cobertura da terra.

A simulação gerada para o ano de 2008 possui satisfatória similaridade com o mapa de referência, mostrando o potencial da aplicação do modelo ora apresentado para o estudo de mudanças de cobertura e uso da terra. As simulações prospectivas de 2009 a 2012, produzidas por cenários estacionários, passíveis de serem extrapoladas para horizontes de projeto mais distantes, representam um insumo importante para o ordenamento territorial, bem como para a formulação de políticas públicas de planejamento regional, ambiental e agrícola.

Por fim, cabe salientar que os resultados da aplicação do modelo de autômatos celulares para simular mudanças de uso e cobertura da terra vinculadas à expansão agrícola no município de Campos Novos/SC, para o período de 2003 a 2012, foram alcançados com êxito, confirmando a plena consecução dos objetivos do presente trabalho,

No entanto, é mister mencionar as limitações intrínsecas a modelos de simulação de mudanças de uso e cobertura da terra, a exemplo do seu reducionismo e restrições para capturar integralmente a complexidade inerente à realidade (BRIASSOULIS, 2000). Ademais, a aleatoriedade atrelada aos algoritmos de alocação de mudança, associada à própria 
natureza imprevisível de processos de mudança de uso e cobertura da terra, impede o modelo de gerar simulações que reproduzam a realidade com irrestrita fidedignidade. Contudo, eles oferecem ainda assim uma maneira incomparável de se abstrair padrões, ordem e tendências prevalentes de fenômenos dinâmicos do mundo real (BATTY, 1976; ALMEIDA et al., 2003).

Como sugestão para trabalhos vindouros recomenda-se a utilização de rotinas para o cálculo preciso dos parâmetros de área média, variância da área, percentual de patcher, expander e índice de isometria individualmente para cada transição considerada, assim como para cada algoritmo de alocação de mudança. Além disso, a conjetura de cenários exploratórios e não somente estacionários, contemplando distintos contextos macroeconômicos e de subsídios agrícolas, deverá ser igualmente explorada em investigações futuras.

\section{Referências Bibliográficas}

ALMEIDA, C. M.; BATTY, M.; MONTEIRO, A. M. V.; CAMARA, G.; SOARES-FILHO, B. S.; CERQUEIRA, G. C.; PENNACHIN, C. L. Stochastic Cellular Automata Modelling of Urban Land Use Dynamics: Empirical Development and Estimation. Computers, Environment and Urban Systems, v. 27, n.5, p. 481-509, 2003.

BARBIERI, R. F. As confusões do IBGE e o setor sucroalcooleiro.Valor Econômico, A-14, 2009.

BATTY, Michael.Urban modelling: algorithms, calibrations, predictions. Cambridge, UK: Cambridge University Press, 1976. 381 p.

BATTY, M.; COUCLELIS, H.; EICHEN, M. Urban systems as cellular automata (Editorial).Environment and Planning B, v. 24, n. 2, p. 159-164, 1997.

BONHAM-CARTER, G. F. Geographic Information Systems for Geoscientists: Modelling with GIS. Ontario, EUA: Pergamon, 1994, 305 p.

BRIASSOULIS, H. Analysis of land use change: theoretical and modeling approaches. 2000. Tese (Doutorado em Geografia) - University of Aegean, Lesvos, Grécia. 2000. Disponível em: <http://www.rri.wvu.edu/WebBook/Briassoulis/contents.htm>. Acesso em: 28out. 2014.

CHAKRAVARTY, S.; GHOSH, S. K.; SURESH, C. P.; DEY, A. N.; SHUKLA, G. Deforestation: Causes, Effects and Control Strategies. In: OKLA, C. A. (Ed.). Global Perspectives on Sustainable Forest Management.Shangai: InTech China, 2012. 300p. ISBN: 978-953-51-0569-5. Disponível em: $<$ http://www.intechopen.com/books/globalperspectives-on-sustainable-forestmanagement/deforestation-causes-effects-and-control-strategies>. Acesso em: 23 jul. 2016. EMPRESA BRASILEIRA DE PESQUISA AGROPECUÁRIA (EMBRAPA). Mapa de Solos do Estado de Santa Catarina (escala 1:250.000). Florianópolis: Embrapa, 2005.

FREITAS, R. R.; BELTRAME, A. V. Mudanças no uso e cobertura da terra do entorno da Lagoa de Ibiraquera (Santa Catarina, Brasil) no período de 1957 a 2011. GEOSUL, v. 27, n. 54, p. 77-98, 2012.

GOOGLE INC. Google Earth. Menlo Park, CA, EUA: Google Inc, 2009. Disponível em: <https://www.google.com.br/intl/pt-PT/earth/>.Acesso em: 12 jan. 2009. 
HAGEN, A. Multi-method assessment of map similarity. In: AGILE CONFERENCE ON GEOGRAPHIC INFORMATION SCIENCE, 5., 2003, Palma, Espanha. Anais... Palma: Universitat de les Illes Balears, 2003. p. 171-182.

INSTITUTO BRASILEIRO DE GEOGRAFIA E ESTATÍSTICA (IBGE). Base Cartográfica Contínua 1:250.000 (BC-250). Rio de Janeiro: IBGE, 2011.

Censo Agropecuário 2006/2007: Brasil, grandes regiões e unidades da federação.

Segunda apuração. 758 p. Rio de Janeiro: IBGE, 2012. Disponível em: <https://sidra.ibge.gov.br/pesquisa/censo-agropecuario/censo-agropecuario-2006/segundaapuracao>. Acesso em: 13nov. 2016.

. Manual Técnico de Uso da Terra. Manuais Técnicos em Geociência, n. 7. Brasil.

Rio de Janeiro: IBGE, 2006. 91p.

INSTITUTO NACIONAL DE PESQUISAS ESPACIAIS (INPE). Divisão de Sensoriamento Remoto. TOPODATA - Banco de dados geomorfométricos do Brasil. São José dos Campos, SP: INPE, 2009. Disponível em: <http://www.dsr.inpe.br/topodata〉. Acesso em: 07fev. 2012. PANDOLFO, C.; BRAGA, H.J.; SILVA JÚNIOR, V.P.; MASSIGNAM, A.M.; PEREIRA, E.S.; THOMÉ, V.M.R. Atlas climático digital do Estado de Santa Catarina (CD-ROM). Florianópolis: Epagri, 2002.

PERRINGS, C. Biodiversity, Ecosystem Services, and Climate Change - The Economic Problem. Washington, D.C., EUA: The International Bank for Reconstruction and Development/The World Bank, 2010. 39 p. (Environment Department Papers Environmental Economics Series - Paper Number 120).Disponível em: <http://siteresources.worldbank.org/EXTEEI/Resources/BiodiversityEcosystemsServices_CC .pdf $>$. Acesso em: 12mar. 2016.

PINO, F. A. Análise preliminar de um censo agropecuário: projeto LUPA no Estado de São Paulo. São Paulo: Secretaria de Agricultura e Abastecimento. Coordenadoria de Assistência Técnica Integral. Instituto de Economia Agrícola (SAA/CATI/IEA), 2009. (Relatório Técnico). Disponível em: <http://www.cati.sp.gov.br/projetolupa $>$ ou <http://www.iea.sp.gov.br/projetolupa>. Acesso em: 30 mai. 2009.

MACEDO, R. C.; ALMEIDA, C. M.; SANTOS, J. R.; RUDORFF, B. F. T. Modelagem dinâmica espacial das alterações de cobertura e uso da terra relacionadas à expansão canavieira. Boletim de Ciências Geodésicas, v. 19, p. 313-337, 2013.

PREFEITURA MUNICIPAL DE CAMPOS NOVOS. Município de Campos Novos. Disponível em: 〈http://www.camposnovos.sc.gov.br>. Acesso em: 01dez. 2010.

SILVANO, R. A. M.; UDVARDY, S.; CERONI, M.; FARLEY, J. An ecological integrity assessment of a Brazilian Atlantic Forest watershed based on surveys of stream health and local farmers' perceptions: implications for management. Ecological Economics, v. 53, p. 369-385, 2005.

SOARES-FILHO, B. S.; ASSUNÇÃO, R. M.; PANTUZZO, A. E. Modeling the spatial transition probabilities of landscape dynamics in an Amazonian colonization frontier. BioScience, v. 51, n. 12, p. 1059-1067, 2001.

SOARES-FILHO, B. S.; CERQUEIRA, G. C.; PENNACHIN, C. L. DINAMICA - a stochastic cellular automata model designed to simulate the landscape dynamics in an Amazonian colonization frontier. Ecological Modelling, v. 154, p. 217-235, 2002.

UNIVERSITY OF MARILAND (UMD). GeoCover Technical Guide. Disponível em: <http://glcf.umd.edu/library/guide/techguide_geocover. pdf>. Acesso em: 15 ago. 2017.

WIKIPEDIA - The Free Encyclopedia. Campos Novos. 2012. Disponível em: <https://pt.wikipedia.org/wiki/Campos_Novos>. Acesso em: 05 abr. 2012.

XIMENES, A. C.; ALMEIDA, C. M.; AMARAL, S.; ESCADA, M. I. S.; AGUIAR, A. P. D. Modelagem Dinâmica do Desmatamento na Amazônia. Boletim de Ciências Geodésicas, v. 14, p. 370-391, 2008. 
Recebido em 20 de julho de 2014.

Aceito em 09 de agosto de 2018. 